\title{
The Implementation of Blended Learning with Kelase Platform in the Learning of Assessment and Evaluation Course
}

\author{
https://doi.org/10.3991/ijet.v14i17.8308 \\ Dewa Gede Hendra Divayana \\ Universitas Pendidikan Ganesha, Singaraja, Indonesia \\ hendra.divayana@undiksha.ac.id
}

\begin{abstract}
This research aimed to know the implementation of blended learning with Kelase platform in the learning process of Assessment and Evaluation course. Determination of subjects in this research used purposive sampling technique, with the number of subjects was involved as many as 40 peoples. Methods of data collection in this research used questionnaires, observations, and documentation. The steps were undertaken in this research include (1) selection and personnel training; (2) location selection, hardware installation, and software installation; (3) programming and program testing; (4) system testing; and (5) system conversion. Data analysis technique in this research was quantitative descriptive. The results were obtained in this research showed the effectiveness level percentage of the implementation of blended learning with Kelase platform that was used to support the learning process of Assessment and Evaluation course was $90.2 \%$, so it was included in the very good category.
\end{abstract}

Keywords-Blended Learning, Kelase Platform, Assessment, Evaluation

\section{Introduction}

Currently, the development of learning strategies at the basic, intermediate, and high level has undergone changes in line with advances in information technology. Advancement of information technology has penetrated to various sides of society's life, including also in the field of education. That matter reinforced by the statement of Raja and Nagasubramani [1] in 2018 which states that technology has transformed and revolutionized the field of education through the use of information technology in automating the learning process so that the transfer of knowledge becomes faster and easier.

Some examples of information technology-based learning strategies that can be used in the learning process both at the elementary school level up to college whether implemented in the classroom or outside the class include e-learning, e-teaching, blended learning, and others. In particular, one of the technology-based learning strategies that are currently being used in college is blended learning. The reason for the use of blended learning because the quality of learning can still be maintained through the learning process, which is a combination of face-to-face learning in the classroom with information technology-assisted learning. It needs the right platform following the learning objectives and most importantly is easy to use to be able to operate 
blended learning in college optimally. Some platforms that are familiar and often used to support the implementation of blended learning in college are Edmodo and Moodle.

However, the fact that occurs especially when researchers directly were involved in the learning process with learning strategies used blended learning that utilized of Moodle platform in Assessment and Evaluation course in the Department of Information Technology Education, Universitas Pendidikan Ganesha. Which it shows that not all blended learning that is supported by the Moodle platform can running well and stable, but there are also found its weakness.

The weakness was known when there was a complaint from students that revealed that access to blended learning with Moodle for Assessment and Evaluation course was slow. The weaknesses of Moodle related with slow access, reinforced by the research results in 2018 that was conducted by Ndlovu and Mostert [2] which revealed that: "One of the obstacles from Moodle was the speed of access was slow". Other research results which in essence also indicate the weakness of Moodle that is research conducted by Ivanović et al. [3] in 2009 stated that gaps that often appear in the learning process using Moodle are slow loading when accessed by many users.

Besides used blended learning that utilized the Moodle platform, the researcher has also used Edmodo platform to support the learning process of Assessment and Evaluation course. However, there was also a weakness that appears on the Edmodo platform that was used to support blended learning in the Assessment and Evaluation course was the use of full English on Edmodo platform that causes difficulties in the operation of blended learning for students and lecturers who wasn't understanding about English. The weakness that was found from Edmodo platform was also reinforced by research conducted in 2017 by Gay and Sofyan [4] which in principle states that "the use of language in Edmodo program that is still in English so that sometimes make it difficult for the lecturers and students who have limited knowledge of English".

From some of the problem findings and reinforced by some of the research results that have described previous, then it is necessary to do this research. Besides, based there were the findings of several problems in the utilization of Moodle and Edmodo platforms was in support of the blended learning implementation in universities, it needs to search the innovation to overcome them. The innovation intended is the utilization of Kelase platform in supporting the implementation of blended learning in universities.

Based on the findings of problems and the innovation as its solutions, then the problem statement in this research was: "How did the implementation of blended learning with Kelase platform in supporting the learning process of Assessment and Evaluation course?" From that problem statement, it is clear that the purpose of this research is to know the implementation of blended learning with Kelase platform used in a learning process, especially in the Assessment and Evaluation course at the Department of Information Technology Education, Universitas Pendidikan Ganesha.

Some research results related to this research include: research that was conducted in 2016 by Al-Ajlan and Hammoudeh [5], where the results of their research had similarities with this research in terms of its research focus was about implementation a system/platform that supports learning strategies in universities. The difference lies in the platform was used and the form of its learning strategy, wherein their research 
more focused on the Moodle platform to support the implementation of e-learning, while in this research more focus on Kelase platform to support the implementation of blended learning.

The research of Lin, Tseng, and Chiang in 2017 [6], generally had similarities with this research in terms of its research focus that was about implementation an interactive media in the form of blended learning that could be used to encourage the improvement of education quality in universities. The difference lies in the platform was used to create blended learning, and the courses were packed with blended learning. Where in the research that had been done by Lin, Tseng, and Chiang focus more on the Moodle platform in made the blended learning that was used to support the learning process of Mathematics courses. While in this research, more focus on Kelase platform in made blended learning, which was used to support the learning process of Assessment and Evaluation course.

The research that had been carried out by Wichadee in 2017 [7] had similarities with this research that was in terms of its research focus about the implementation of a platform that supports a form of learning strategy so that it could optimize the process of learning. The difference was on the platform that was used, the form of learning strategies that were used in the learning process, and the location of its implementation. Where, in research conducted by Wichadee focus more on the utilization of Edmodo platform to made e-learning which was implemented in vocational high school, while in this research more focus on utilization of Kelase platform to made blended learning which was implemented in college.

The research that was conducted in 2017 by Patmanthara and Hidayat [8] had similarities with this research in terms of its research focus in the implementation a system/platform used to create blended learning in supporting the learning process. The difference lies in the platform used in making blended learning and the location of the implementation of blended learning. Research conducted by Patmanthara and Hidayat more focus on utilization of Edmodo platform to made blended learning and location of its implementation in vocational high school, while in this research more focus on Kelase platform utilization to made blended learning and its implementation location focused on college.

\section{$2 \quad$ Literature Review}

\subsection{Blended learning}

Based on research that was conducted by Lalima and Dangwal in 2017 [9], it was stated that "blended learning is an innovative concept that seeks to combine offline learning in the classroom with online learning through ICT support that can be done outside the classroom". That statement reinforced with the Shivam and Singh's research in 2015 [10] which states that "blended learning is a combination that occurs between traditional learning carried out face-to-face with online learning conducted via the internet". 
According to some definitions above, it can be generated the general conclusion that blended learning is a learning strategy which combines between conventional learning and information technology-based learning, in which learning process can be conducted effectively and with good interaction quality between the lecturers and the students.

\subsection{Kelase}

Kelase is private social networks at the same time online learning environment for institutions education and organization. Kelase developed by PT. Edukasi 101 (one of the private companies in Indonesia with business scope in the field of education) to improve the quality of education and training as well as the productivity of the organization in Indonesia [11]. Kelase's service allows educators to create online classes for their students, so if the educator had not been physically present in the classroom, he could teach from anywhere as long as he had an internet connection [12]. The features available on Kelase, such as

- Social features which are used to share status messages, links and photos/images on your page, institutions/organizations, and classes, provide comments, like and function friendship

- Collaboration features used for making activities together on a private page and community and also conduct discussions

- Features of information and communication used to receive news and comment on the page of news from agencies/organizations, as well as send and receive private messages

- Learning function which is used to create and follow the online classroom learning with various learning activities, such as the reading/blog, tasks, quiz, and discussion forum [11].

From those explanations, it can be concluded that Kelase is one platform with a similar shape as a social network developed by an organization called PT. Edukasi 101 from Indonesia, where it can be used to create online classes for several levels of education ranging from elementary to university that is not paid/free equipped with several features, including social features; collaboration features; features of information and communication; and learning function. The language of instruction used in each feature on the Kelase platform is mostly Indonesian.

\subsection{Assessment}

According to Fuentealba [13], Assessment is a tool used to determine the level of learning that has been achieved by students with standard reference and curricular objectives. Wiliam [14] states that only through the assessment process, we can know the success of learning activities. Based on several statements about those assessment, can get a general conclusion that the assessment is an activity conducted to interpret data measurement results of students' ability in following the learning process. 


\subsection{Evaluation}

According to Aziz, Mahmood, and Rehman [15], "evaluation is an activity carried out to determine the quality and effectiveness of education to fit the expected objectives". Marlina, Putri, and Darmawijoyo [16] stated that evaluation is a stage to see the effectiveness of a program, whether it has been running following the initial expectations had set or not following initial expectations.

Based on several explanations related to the definition of evaluation mentioned above, a general conclusion can be get that evaluation is an activity carried out by evaluators in a comprehensive and structured in collecting, processing, analyzing, and presenting data into valuable information in order to facilitate policy makers in making a decision whether a program is still running or not.

\section{Research Methodology}

\subsection{Object of the research}

The object of this research was blended learning with Kelase platform. The reason for the selection of blended learning with Kelase platform as the object of research because it is a new form of innovation in overcoming the problems that were found in information technology-based learning strategies (such as e-learning or blended learning) that had been developed previously using Moodle or Edmodo in other studies.

\subsection{Subject of the research}

Subjects were involved in this research was 40 peoples, consist of one lecturer and 39 students who take the Assessment and Evaluation course. The technique that was used in the selection of subjects in this research used purposive sampling. The using of the purposive sampling technique was to it easier in determine of the stakeholders and the parties which were involved directly in the learning process of Assessment and Evaluation course, so that the data collecting process would be more focused and directed.

\subsection{Location of the research}

The location of this research was conducted at the Department of Information Technology Education, Faculty of Engineering and Vocational, Universitas Pendidikan Ganesha. The reason for choosing the research location in this place because the initial problem about the obstacle of slow access in the utilization of blended learning with the Moodle platform occurs during the learning process of Assessment and Evaluation course that was conducted in the Department of Information Technology Education, Universitas Pendidikan Ganesha. Therefore, an innovation of Kelase platform utilization should also be tested at the same location (Department of Information Technology Education, Universitas Pendidikan Ganesha) to found out how far the 
effectiveness of Kelase platform utilization can support the learning process of the Assessment and Evaluation course.

\subsection{Methods of collecting data}

The method that was used in data collection in this research used questionnaires, documentation, and observation. The questionnaires were used to know the result of user response to blended learning with Kelase platform, which was used to support the learning process of Assessment and Evaluation course. Documentation was used to document the forms of Kelase platform display that used to create blended learning of Assessment and Evaluation course. The observation was done to find out directly the activities of the students during the learning process used blended learning with Kelase platform. Existence of the data collected well and valid through the questionnaires, documentation, and observations that had been done during this research could be made it easier in the process of analyzing data research results.

\subsection{Design of the research}

The stages that were carried out in implementing blended learning with the Kelase Platform used to support the learning process of the Assessment and Evaluation course consist of five stages. Those stages can be seen completely in Figure 1.

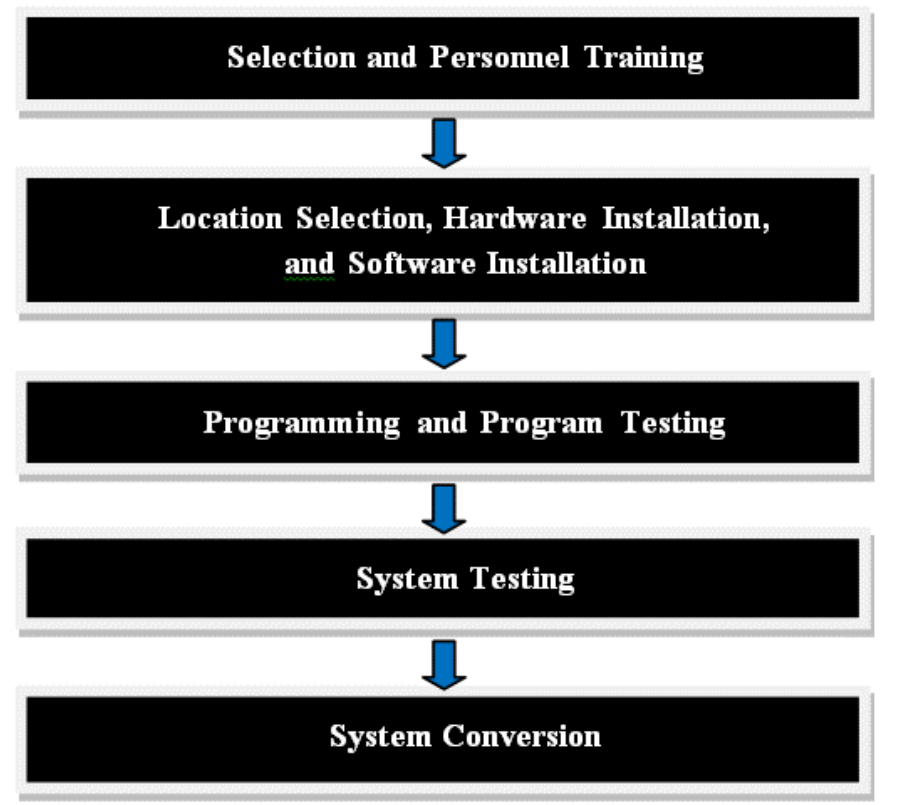

Fig. 1. Stages in Implementing the Blended Learning with Kelase Platform 


\subsection{Technique data analysis}

The technique that was used to analyze the data result of this research was descriptive quantitative by using percentage descriptive calculation. The formula used to calculate of percentage descriptive is follows [17].

$$
\text { Percentage }=\frac{\sum(\text { Answer } * \text { Weight of Each Answer })}{\mathrm{n} * \text { Highest Weight }} * 100 \%
$$

Notes:

$\sum \quad=$ Sum

$\mathrm{n} \quad=$ the total number of questionnaires

The results of the descriptive percentage need to converted into the categorization of effectiveness rate by scale's five to easier interpreted. That categorization completely can be seen in Table 1 .

Table 1. The Categorization of Effectiveness Rate Refers to Scale's Five

\begin{tabular}{|c|l|}
\hline Effectiveness Level & \\
\hline $90-100 \%$ & Category \\
\hline $80-89 \%$ & Good \\
\hline $65-79 \%$ & Sufficient \\
\hline $55-64 \%$ & Deficient \\
\hline $0-54 \%$ & Poor \\
\hline
\end{tabular}

\section{$4 \quad$ Results and Discussion}

\subsection{Results}

The research results were obtained by reference based on the findings of the problem and the stages of system implementation. The research results could be seen as follows.

Selection and Personnel Training: Personnel that was selected and given training using the Kelase platform for blended learning that supports the learning process of the Assessment and Evaluation course come from lecturers and students of information technology education department. The selected personnel can be seen in Table 2.

Location selection and installation of hardware and software: The location was chosen in the implementation of Kelase platform for blended learning in supporting the learning process of Assessment and Evaluation course was FTK-1.3 and FTK-1.4 room on Faculty of Engineering and Vocational, Universitas Pendidikan Ganesha. The hardware and software installation process of Kelase platform that was used to create blended learning of Assessment and Evaluation course wasn't necessary, because this platform can be accessed directly and it is free via the following URL: https://www.kelase.com/. 
Table 2. The Data of Personnel that was Selected and Given Training in the Using of the Kelase platform

\begin{tabular}{|c|c|c|c|}
\hline No & Personnel Code & Status & Access Rights \\
\hline 1 & L-01 & Lecturer & Admin/User \\
\hline 2 & S-01 & Student & User \\
\hline 3 & $\mathrm{~S}-02$ & Student & User \\
\hline 4 & S-03 & Student & User \\
\hline 5 & S-04 & Student & User \\
\hline 6 & S-05 & Student & User \\
\hline 7 & S-06 & Student & User \\
\hline 8 & S-07 & Student & User \\
\hline 9 & S-08 & Student & User \\
\hline 10 & S-09 & Student & User \\
\hline 11 & S-10 & Student & User \\
\hline 12 & S-11 & Student & User \\
\hline 13 & S-12 & Student & User \\
\hline 14 & S-13 & Student & User \\
\hline 15 & S-14 & Student & User \\
\hline 16 & S-15 & Student & User \\
\hline 17 & S-16 & Student & User \\
\hline 18 & S-17 & Student & User \\
\hline 19 & S-18 & Student & User \\
\hline 20 & S-19 & Student & User \\
\hline 21 & S-20 & Student & User \\
\hline 22 & S-21 & Student & User \\
\hline 23 & S-22 & Student & User \\
\hline 24 & S-23 & Student & User \\
\hline 25 & S-24 & Student & User \\
\hline 26 & S-25 & Student & User \\
\hline 27 & S-26 & Student & User \\
\hline 28 & S-27 & Student & User \\
\hline 29 & S-28 & Student & User \\
\hline 30 & S-29 & Student & User \\
\hline 31 & $\mathrm{~S}-30$ & Student & User \\
\hline 32 & S-31 & Student & User \\
\hline 33 & S-32 & Student & User \\
\hline 34 & S-33 & Student & User \\
\hline 35 & S-34 & Student & User \\
\hline 36 & S-35 & Student & User \\
\hline 37 & S-36 & Student & User \\
\hline 38 & S-37 & Student & User \\
\hline 39 & S-38 & Student & User \\
\hline 40 & S-39 & Student & User \\
\hline
\end{tabular}

Programming and program testing: Generally, the programming and testing stage of the program didn't need to was conducted again in this research, because Kelase platform had been created and tested directly by its developer that was PT. Edukasi 101 since its establishment in 2013. However, particularly in this stage would be shown about the display of the forms needed to support the learning process of 
Assessment and Evaluation course. Some display of those forms intended can be shown follows.

The Main Menu Display: The main menu display of Kelase platform can be seen in Figure 2. To enter the main menu view, then first visit the following URL: https://www.kelase.com/.

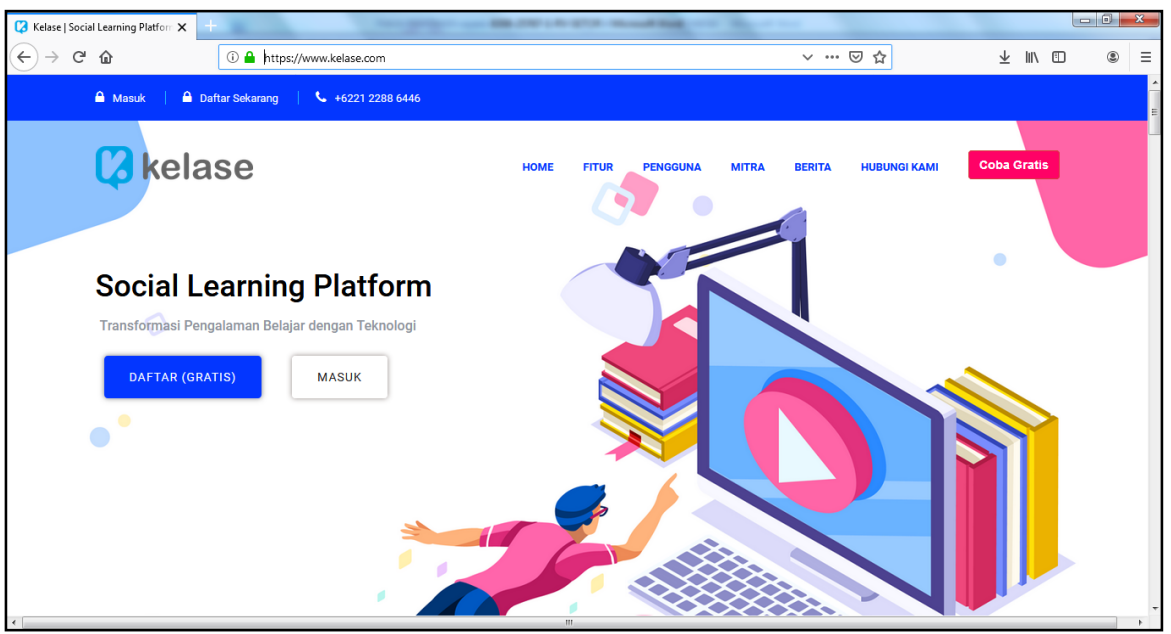

Fig. 2. The Main Menu Display of Kelase Platform

The display of institution registration form: This form is used to register the identity of the platform user institution. The form display to register the name of the institution on Kelase platform can be seen in Figure 3.

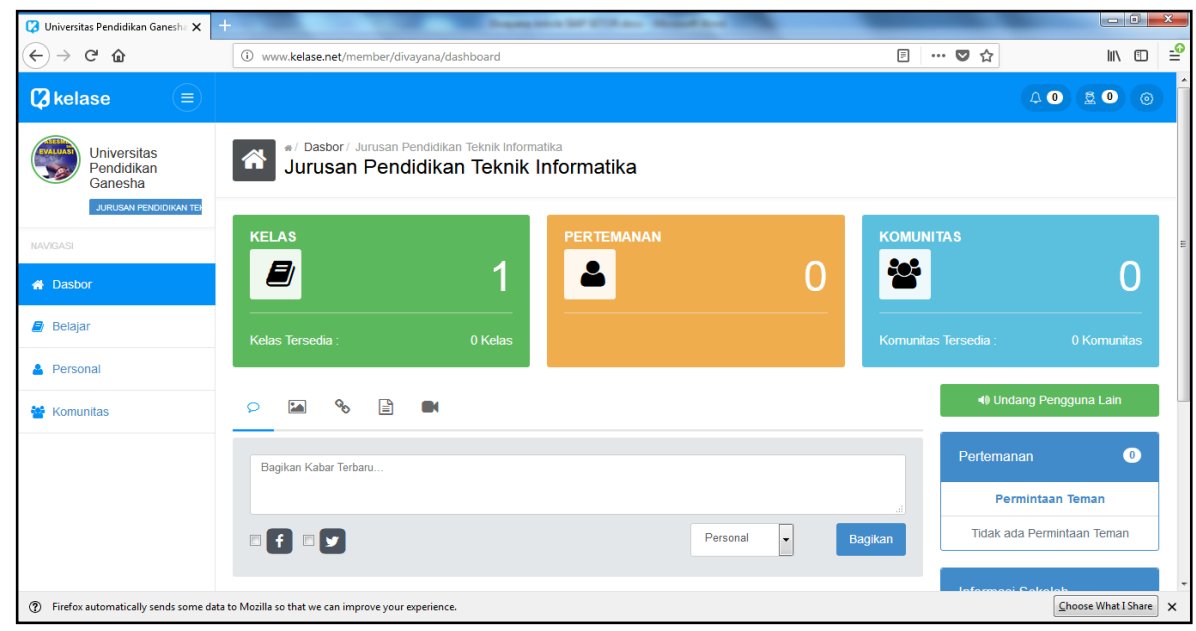

Fig. 3. The Display of Institution Registration Form in Kelase Platform 
The display of assessment and evaluation class form: The form display of Assessment and Evaluation class can be seen in Figure 4. This form is used to create the class name (especially in this research focused on the assessment and evaluation class).

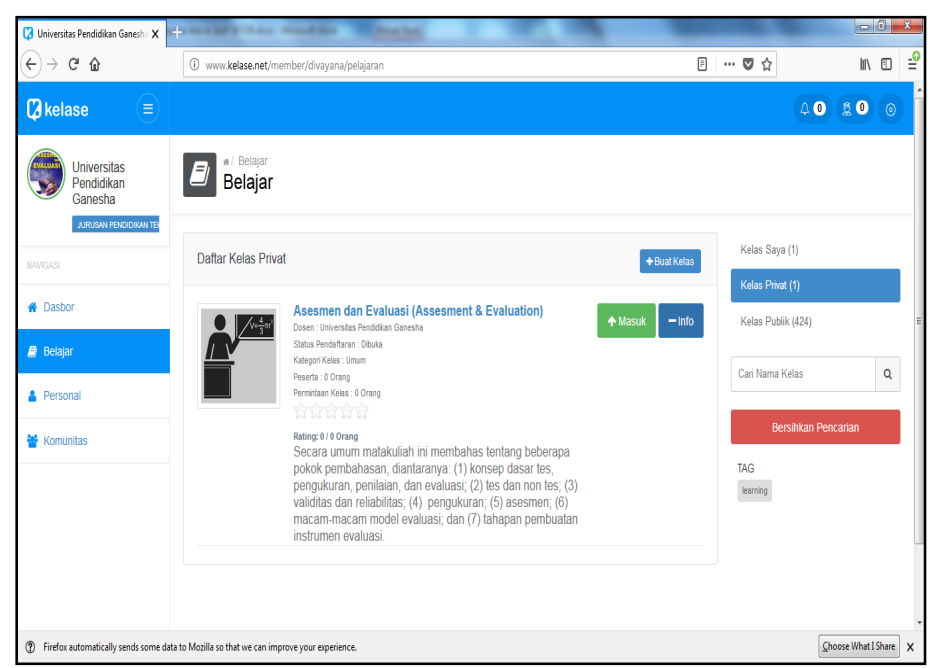

Fig. 4. The Form Display of Assessment and Evaluation Class in Kelase Platform

The display of student data form in assessment and evaluation class: The display of the student data input form into Assessment and Evaluation class can be seen in Figure 5. This form is used to enter the student's data who following the learning process in assessment and evaluation class.

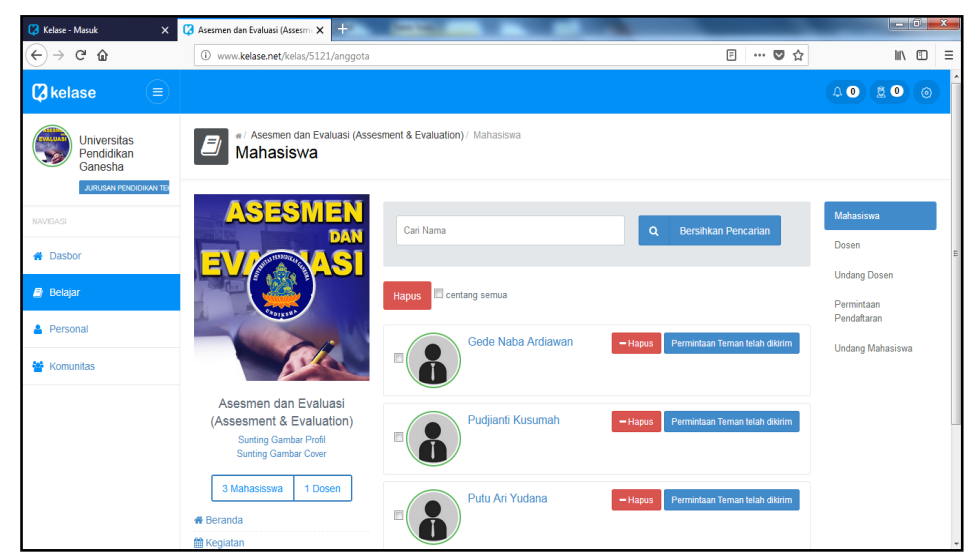

Fig. 5. The Form Display of Student's Data in Assessment and Evaluation Class 
The form display of discussion forum: The display of discussion forum form in the class can be seen in Figure 6. This form is used to display discussion forums conducted by lecturers with students in the learning process.

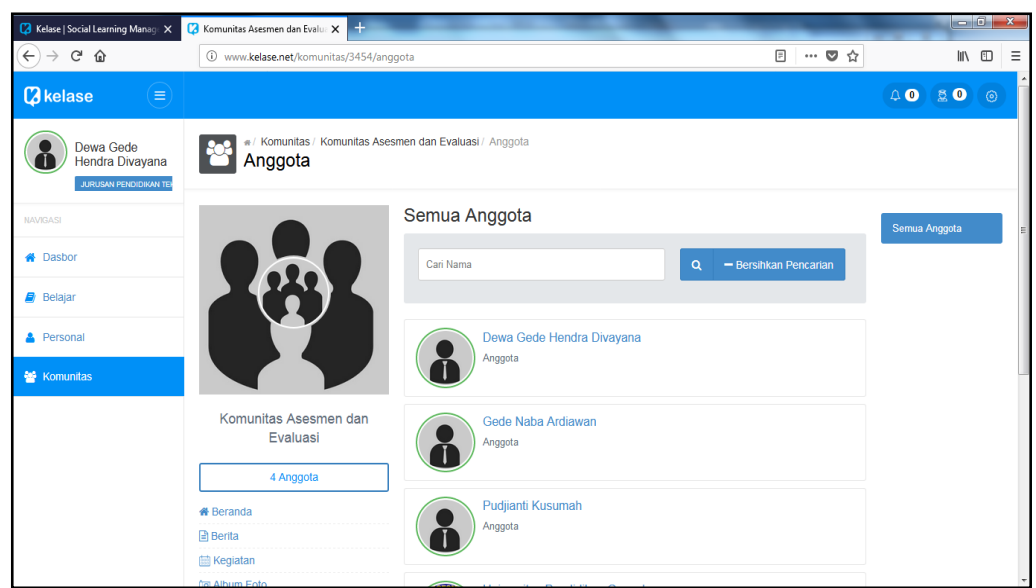

Fig. 6. The Form Display of Discussion Forum in Kelase Platform

The form display for inserting the learning material: The form display of learning material that had been inputted can be seen in Figure 7. This form is used to enter the learning material needed in the learning process in the Assessment and Evaluation course.

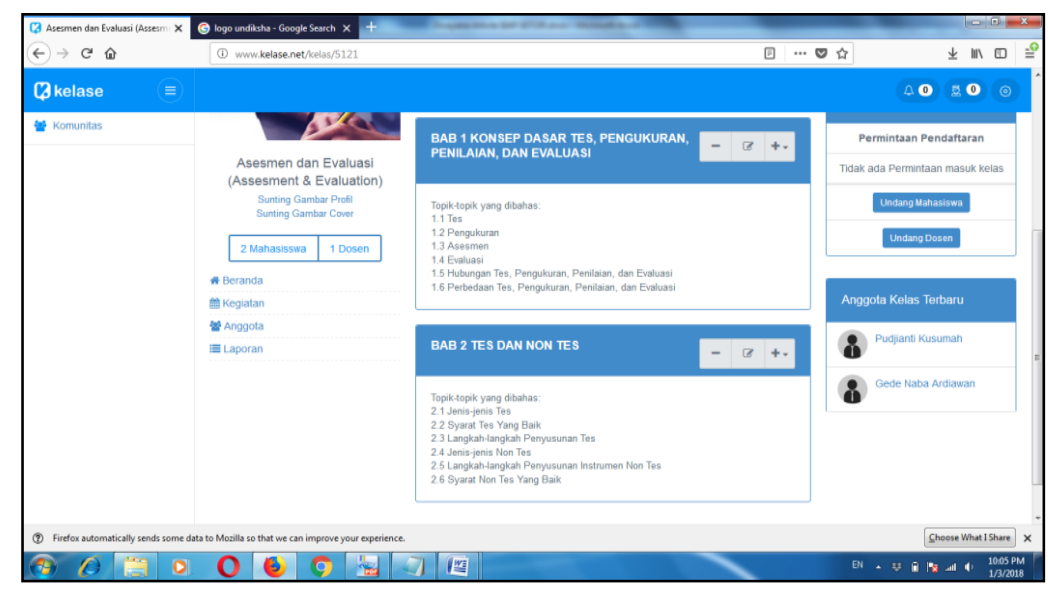

Fig. 7. The Form Display for Input the Learning Material in Kelase Platform

The material was entered into the Kelase platform was Assessment and Evaluation material. The source material was from a textbook entitled "ASESMEN DAN EVALUASI" (Assessment and Evaluation) by Dewa Gede Hendra Divayana. The cover view of that textbook can be seen in Figure 8. 

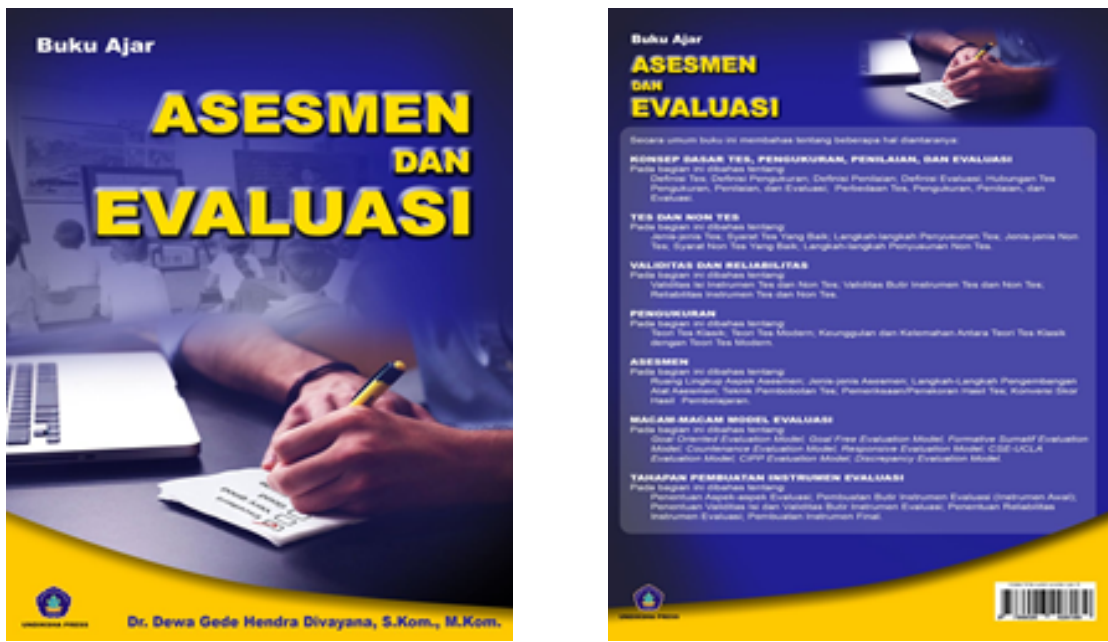

Fig. 8. The Cover View of Textbook for Learning Material of Assessment and Evaluation Course

Details of the material in the Assessment and Evaluation textbook that was uploaded into the Kelase platform consist of

- Chapter 1: Basic Concepts of Testing, Measurement, Assessment, and Evaluation. In this chapter 1, it consists of several sub-chapters, including:

- Tests

- Measurements

- Assessment

- Evaluation

- Relationships between Test, Measurements, Assessments, and Evaluations

- Differences between Test, Measurement, Assessment, and Evaluation

- Chapter 2: Testing and Non-Testing. In this chapter 2, it consists of several subchapters, including:

- Types of Tests

- Requirements for a Good Test

- Test Preparation Stages

- Non-Test Types

- Development Stages of Non-Test Instrument

- Requirements for a Good Non-Test

- Chapter 3: Validity and Reliability. In this chapter 3, it consists of several subchapters, including:

- Content Validity of Test and Non-Test Instruments

- Validity of Test and Non-Test Instruments

- Reliability of Test and Non-Test Instruments 
- Chapter 4: Measurement. In chapter 4 it consists of several sub-chapters, including:

- Classical Test Theory

- Modern Test Theory

- The Advantages and Weaknesses between Classical Test Theory and Modern Test Theory

- Chapter 5: Assessment. This chapter 5 it consists of several sub-chapters, including:

- Scope of Assessment Aspects

- Types of Assessment

- Assessment Tool Development Steps

- Techniques of Test Weighted

- Scoring of Test Results

- Conversion of Learning Results Scores

- Chapter 6: Various evaluation models. In chapter 6 it consists of several subchapters, including:

- Goal Oriented Evaluation Model

- Goal-Free Evaluation Model

- Formative Summative Evaluation Model

- Countenance Evaluation Model

- Responsive Evaluation Model

- CSE-UCLA (Center for the Study of Evaluation-University of California in Los Angeles) Evaluation Model

- CIPP (Context, Input, Process, and Product) Evaluation Model

- Discrepancy Model

- Chapter 7: The Stages of Creating the Evaluation Instruments. In chapter 7 it consists of several sub-chapters, including:

- Determination of Evaluation Aspects

- Preparation of Evaluation Instruments (Initial Instruments)

- Determination of Content Validity and the Items Validity of Evaluation Instruments

- Determination of Reliability the Evaluation Instruments

- Creating the Final Instruments.

The display of assignment form for the students: The display of the form to provide assignments to students can be seen in Figure 9. This form is used to facilitate lecturers in giving assignments to students. 


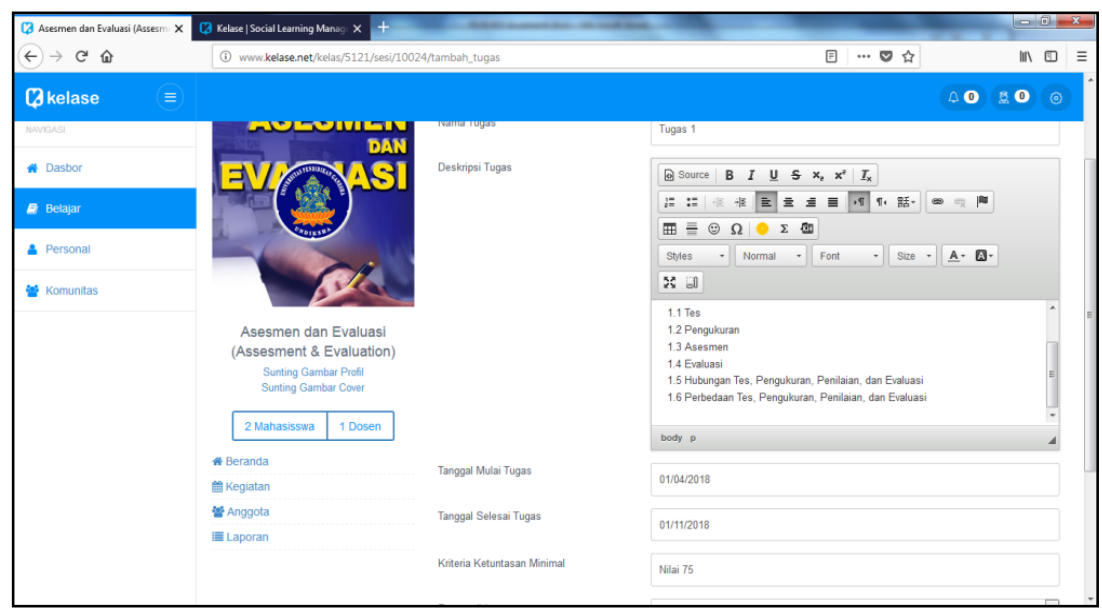

Fig. 9. The Display of Assignment Form for the Students in Kelase Platform

The display of quiz form: The form display to provide the Quiz for students can be seen in Figure 10. The form is used to facilitate lecturers in giving quizzes to students.

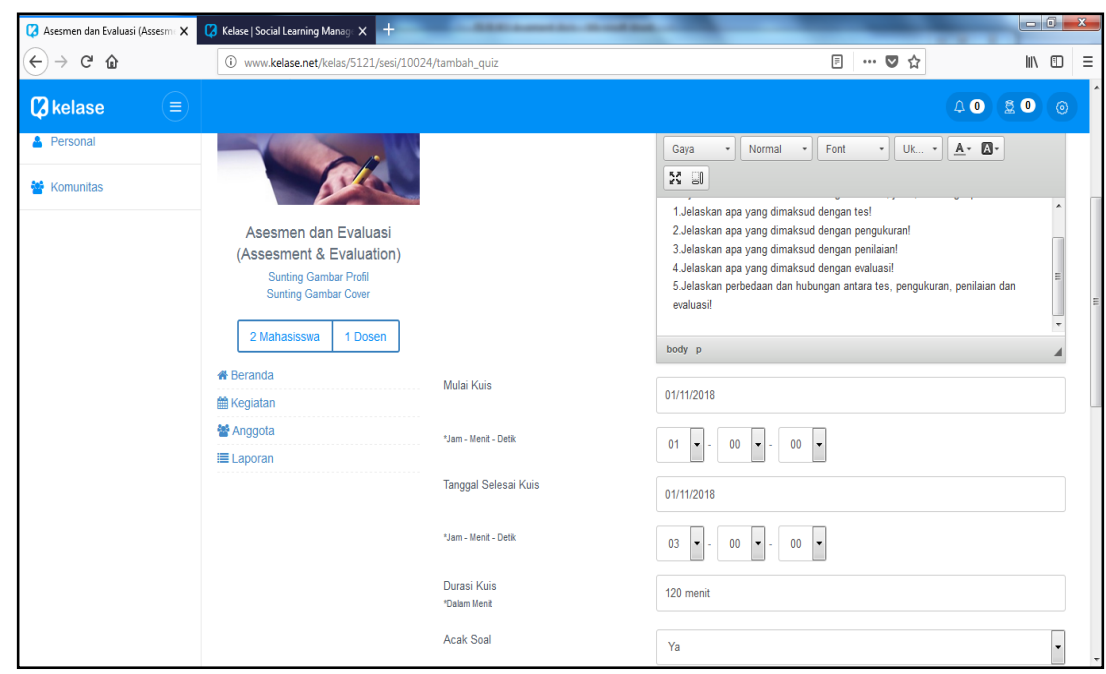

Fig. 10.The Form Display of Quiz for Students in Kelase Platform

The display of learning achievement report form: The form display to see students learning achievement report can be seen in Figure 11. This form is used to view the reports of student learning achievement after completing assignments and quizzes/tests given by the lecturer in the learning process of the Assessment and Evaluation course. 


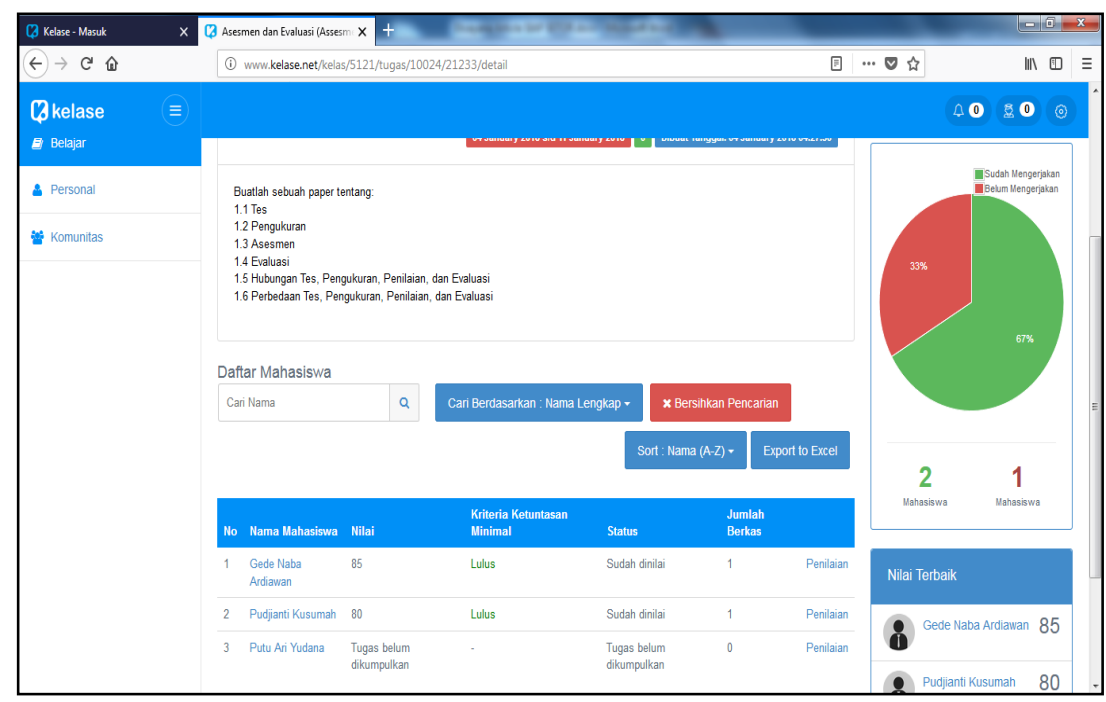

Fig. 11.Display of Learning Achievement Report Form in Kelase Platform

System testing: In this stage, the system had been tested through the results of user response to the implementation of Kelase platform for blended learning that was used in supporting the learning process of Assessment and Evaluation course. The results of user testing on Kelase platform implementation can be seen in Table 3.

Table 3. User Response to the Utilization of the Kelase Platform

\begin{tabular}{|c|c|c|c|c|c|c|c|c|c|c|c|c|}
\hline \multirow{2}{*}{ No } & \multirow{2}{*}{ Personnel Code } & \multicolumn{10}{|c|}{ Items- } & \multirow{2}{*}{$\%$} \\
\hline & & 1 & 2 & 3 & 4 & 5 & 6 & 7 & 8 & 9 & 10 & \\
\hline 1 & L-01 & 5 & 5 & 4 & 5 & 4 & 5 & 4 & 5 & 5 & 5 & 94.0 \\
\hline 2 & S-01 & 4 & 5 & 4 & 5 & 4 & 5 & 5 & 5 & 4 & 5 & 92.0 \\
\hline 3 & S-02 & 5 & 4 & 5 & 4 & 4 & 5 & 4 & 5 & 5 & 4 & 90.0 \\
\hline 4 & S-03 & 4 & 5 & 4 & 5 & 4 & 5 & 5 & 5 & 4 & 5 & 92.0 \\
\hline 5 & S-04 & 5 & 5 & 4 & 5 & 4 & 5 & 4 & 4 & 5 & 4 & 90.0 \\
\hline 6 & S-05 & 4 & 4 & 5 & 5 & 4 & 5 & 4 & 5 & 5 & 5 & 92.0 \\
\hline 7 & S-06 & 5 & 4 & 4 & 5 & 3 & 5 & 4 & 4 & 5 & 5 & 88.0 \\
\hline 8 & S-07 & 5 & 4 & 4 & 5 & 4 & 4 & 4 & 4 & 5 & 5 & 88.0 \\
\hline 9 & S-08 & 5 & 4 & 5 & 4 & 4 & 5 & 4 & 5 & 4 & 5 & 90.0 \\
\hline 10 & S-09 & 5 & 5 & 4 & 5 & 4 & 5 & 4 & 5 & 4 & 5 & 92.0 \\
\hline 11 & S-10 & 4 & 5 & 4 & 4 & 4 & 5 & 5 & 4 & 4 & 5 & 88.0 \\
\hline 12 & S-11 & 5 & 4 & 5 & 5 & 4 & 4 & 4 & 5 & 5 & 4 & 90.0 \\
\hline 13 & S-12 & 4 & 5 & 4 & 5 & 3 & 5 & 5 & 4 & 5 & 5 & 90.0 \\
\hline 14 & S-13 & 5 & 4 & 5 & 5 & 4 & 5 & 4 & 5 & 4 & 5 & 92.0 \\
\hline 15 & S-14 & 5 & 4 & 5 & 5 & 4 & 4 & 4 & 5 & 4 & 5 & 90.0 \\
\hline 16 & S-15 & 4 & 5 & 5 & 5 & 4 & 5 & 5 & 4 & 5 & 4 & 92.0 \\
\hline 17 & S-16 & 5 & 4 & 4 & 4 & 4 & 4 & 4 & 5 & 4 & 5 & 86.0 \\
\hline 18 & S-17 & 4 & 4 & 5 & 4 & 4 & 5 & 4 & 5 & 4 & 5 & 88.0 \\
\hline 19 & S-18 & 5 & 5 & 4 & 5 & 4 & 5 & 4 & 5 & 4 & 5 & 92.0 \\
\hline 20 & S-19 & 4 & 4 & 5 & 5 & 3 & 4 & 4 & 4 & 5 & 5 & 86.0 \\
\hline 21 & S-20 & 4 & 4 & 5 & 5 & 4 & 5 & 5 & 4 & 5 & 4 & 90.0 \\
\hline
\end{tabular}




\begin{tabular}{|c|c|c|c|c|c|c|c|c|c|c|c|c|}
\hline \multirow{2}{*}{ No } & \multirow{2}{*}{ Personnel Code } & \multicolumn{10}{|c|}{ Items- } & \multirow{2}{*}{ \% } \\
\cline { 2 - 14 } & & $\mathbf{1}$ & $\mathbf{2}$ & $\mathbf{3}$ & $\mathbf{4}$ & $\mathbf{5}$ & $\mathbf{6}$ & $\mathbf{7}$ & $\boldsymbol{8}$ & $\mathbf{9}$ & $\mathbf{1 0}$ & \\
\hline 22 & S-21 & 4 & 5 & 5 & 5 & 3 & 5 & 4 & 4 & 5 & 5 & 90.0 \\
\hline 23 & S-22 & 5 & 4 & 5 & 4 & 3 & 4 & 5 & 4 & 4 & 5 & 86.0 \\
\hline 24 & S-23 & 5 & 5 & 4 & 5 & 3 & 5 & 4 & 5 & 5 & 4 & 90.0 \\
\hline 25 & S-24 & 4 & 5 & 4 & 5 & 4 & 5 & 5 & 4 & 5 & 5 & 92.0 \\
\hline 26 & S-25 & 5 & 4 & 4 & 5 & 4 & 4 & 4 & 5 & 5 & 5 & 90.0 \\
\hline 27 & S-26 & 4 & 5 & 4 & 4 & 4 & 5 & 4 & 5 & 5 & 4 & 88.0 \\
\hline 28 & S-27 & 5 & 4 & 5 & 5 & 4 & 5 & 4 & 5 & 4 & 5 & 92.0 \\
\hline 29 & S-28 & 5 & 5 & 4 & 5 & 4 & 5 & 5 & 4 & 5 & 5 & 94.0 \\
\hline 30 & S-29 & 5 & 4 & 5 & 5 & 4 & 4 & 4 & 5 & 4 & 4 & 88.0 \\
\hline 31 & S-30 & 5 & 4 & 4 & 5 & 4 & 5 & 4 & 5 & 5 & 5 & 92.0 \\
\hline 32 & S-31 & 4 & 5 & 5 & 5 & 4 & 5 & 4 & 5 & 4 & 5 & 92.0 \\
\hline 33 & S-32 & 5 & 5 & 4 & 4 & 4 & 4 & 5 & 4 & 5 & 4 & 88.0 \\
\hline 34 & S-33 & 5 & 4 & 4 & 5 & 4 & 5 & 4 & 5 & 4 & 5 & 90.0 \\
\hline 35 & S-34 & 4 & 4 & 5 & 5 & 4 & 5 & 4 & 4 & 5 & 5 & 90.0 \\
\hline 36 & S-35 & 4 & 5 & 4 & 5 & 3 & 5 & 5 & 5 & 4 & 4 & 88.0 \\
\hline 37 & S-36 & 5 & 4 & 5 & 5 & 4 & 4 & 4 & 5 & 5 & 5 & 92.0 \\
\hline 38 & S-37 & 4 & 5 & 4 & 4 & 4 & 5 & 5 & 4 & 5 & 4 & 88.0 \\
\hline 39 & S-38 & 5 & 5 & 4 & 5 & 4 & 5 & 5 & 4 & 5 & 5 & 94.0 \\
\hline 40 & S-39 & 4 & 5 & 5 & 5 & 4 & 5 & 4 & 5 & 4 & 4 & 90.0 \\
\hline & Percentage Average & 91.5 & 90.0 & 89.0 & 95.5 & 76.5 & 95.0 & 86.5 & 92.0 & 91.5 & 94.0 & 90.2 \\
\hline
\end{tabular}

Notes:

Item-1 : $\quad$ Easy access to blended learning with Kelase platform.

Item-2 : $\quad$ Completeness of features available on blended learning with Kelase platform.

Item-3 : $\quad$ Interesting design view.

Item-4 : $\quad$ Blended learning access speed with Kelase platform.

Item-5 : $\quad$ Completeness and depth of the material content of Assessment and Evaluation that

was presented.

Item-6 :

learning material.

Item-7 : Availability of assessment results for assignments and quizzes/tests in each chapter of Assessment and Evaluation learning material.

Item-8 : $\quad$ The language used to easier the operation of blended learning

Item-9 : $\quad$ Blended learning with Kelase platform can increase students' enthusiasm or interest

to learn.

Item-10 : $\quad$ Level of approval to keep using blended learning with Kelase platform in supporting the learning process of the Assessment and Evaluation course.

System Conversion: In this research, the system conversion stage was conducted by using pilot approach, which was begun by the use of blended learning which was created with Kelase platform to support the learning process of Assessment and Evaluation course. If the use of blended learning with Kelase platform was running well, following the learning purpose and increase students' interest to learn, then the implementation of blended learning with Kelase platform is continued to support the learning process of Assessment and Evaluation course or even for other courses.

\subsection{Discussion}

Based on the research results described above, it could be said that there were 40 personnel selected and involved in the introduction and training of the use of blended learning with Kelase platform. After the introduction and operation of the use of 
blended learning with Kelase platform, the next was conducted the system testing. The test result of the system was obtained through the response from 40 users to blended learning with Kelase platform, where the users' response result showed the percentage average was $90.2 \%$ so that generally the implementation of blended learning with Kelase platform was very good if was reviewed based on the categorization of effectiveness rate that refers to scale's five.

The results of this research have been able to provide solution/answer related to problems about slow access when using Moodle platform found in previous research that was conducted by Ndlovu and Mostert in 2018 [2], and research that was conducted by Ivanović et al. in 2009 [3]. The results of this research had answered the problems found in those two previous kinds of research, which was shown with the percentage obtained on item- 4 about the access speed when using Kelase platform was $95.5 \%$ so including to very good category.

The results of this research were also able to provide a solution to the problems found in research that was conducted by Gay and Sofyan in 2017 [4] related to the constrained in blended learning that used full English in Edmodo platform for users who had weaknesses in English. The result of this research was the solution/answer to that problem. It was indicated from the percentage obtained on the item number- 8 about the language was used in blended learning operation with Kelase platform was $92.0 \%$, so it was also very good categorized.

Although the results of this research had been able to provide solutions/answers for some constraints found in other researches, in this research also was found the obstacles in the material content was presented in the blended learning that wasn't depth. It was shown in the percentage obtained on item- 5 about the completeness and depth of the material content of Assessment and Evaluation course that was presented in blended learning with Kelase platform was $76.5 \%$ so that it was categorized as sufficient.

\section{Conclusion}

Generally, the implementation of blended learning with Kelase platform was very good implemented to support the learning process of Assessment and Evaluation course. This platform is very easy and fast to access, easy to be understood by users who have limitations in English, and equipped with full features needed in the process learning, such as: features to facilitate the user in uploading and downloading the learning material, features to facilitate the lecturer in uploading the tests/quiz on each chapter of the learning material, features to facilitate the student to answer the tests/quiz and see the assessment result of the tests/quiz that had been answered, features to facilitate the interaction or communication between lecturers and students, and also features to facilitate the communication between students who follow the group/class. The recommendations given to overcome the obstacles in this research were related to the lack of depth in the material content it is by searching the Assessment and Evaluation materials from various sources either from books or journals 
related to Assessment and Evaluation so that the material can be more extensive and deep.

\section{Acknowledgement}

Thanks to all parties and the academic community of Universitas Pendidikan Ganesha who had provided assistance and support in completing this research. The whole work of this research, dedicated to Universitas Pendidikan Ganesha specifically and dedicated to the advanced of education in Indonesia generally.

\section{$7 \quad$ References}

[1] Raja, R., \& Nagasubramani, P. C. (2018). Impact of Modern Technology in Education. Journal of Applied and Advanced Research, 3(1), 33-35. https://doi.org/10.21839/jaar.20 18.v3iS1.165

[2] Ndlovu, M.C. \& Mostert, I. (2018). Teacher Perceptions of Moodle and Throughput in A Blended Learning Programme for In-Service Secondary School Mathematics Teachers. Africa Education Review, 15(2), 131-151. https://doi.org/10.1080/18146627.2016.1241 $\underline{667}$

[3] Ivanović, M., Welzer, T., Putnik, Z., Hölbl, M., Komlenov, Ž., Pribela, I., \& Schweighofer, T. (2009). Experiences and Privacy Issues - Usage of Moodle in Serbia and Slovenia. Conference ICL2009. Villach-Austria, September 23 -25. ICL 2009 Proceedings, pp. 1-8.

[4] Gay, E., \& Sofyan, N. (2017). The Effectiveness of Using Edmodo in Enhancing Students' Outcomes in Advance Writing Course of the Fifth Semester at FIP - UMMU. Journal of English Education, 2(1), 1-11. https://doi.org/10.31327/jee.v2i1.217

[5] Al-Ajlan, A.S., \& Hammoudeh, M.A.A. (2016). Enhancing E-Learning System in Qassim University by Implementing Moodle as A Tool. International Journal of Computer Science and Network Security, 16(9), 7-14.

[6] Lin, Y.W., Tseng, C.L., \& Chiang, P.J. (2017). The Effect of Blended Learning in Mathematics Course. EURASIA Journal of Mathematics Science and Technology Education, 13(3), 741-770. https://doi.org/10.12973/eurasia.2017.00641a

[7] Wichadee, S. (2017). A Development of the Blended Learning Model Using Edmodo for Maximizing Students' Oral Proficiency and Motivation. International Journal of Emerging Technologies in Learning, 12(2), 137-154. https://doi.org/10.3991/ijet.v12i02.6324

[8] Patmanthara, S., \& Hidayat, W.N. (2017). Improving Vocational High School Students Digital Literacy Skill through Blended Learning Model. 2nd International Conference on Statistics, Mathematics, Teaching, and Research 2017. Makassar, Indonesia, October 9-10. IOP Conf. Series: Journal of Physics: Conf. Series 1028, pp. 1-7. https://doi.org/10.1088/ $\underline{1742-6596 / 1028 / 1 / 012076}$

[9] Lalima, \& Dangwal, K.L. (2017). Blended Learning: An Innovative Approach. Universal Journal of Educational Research, 5(1), 129-136. https://doi.org/10.13189/ujer.2017.050116

[10] Ruchi Shivam, R., \& Singh, S. (2015). Implementation of Blended Learning in Classroom: A Review Paper. International Journal of Scientific and Research Publications, 5(11), 369372.

[11] https://kelase.com/ (accessed on 03rd July 2019).

[12] https://id.techinasia.com/kelase-mobile-lab-microsoft (accessed on 03rd July 2019). 
[13] Fuentealba, C. (2011). The Role of Assessment in the Student Learning Process. Journal of Veterinary Medical Education, 38(2),157-62. https://doi.org/10.3138/jvme.38.2.157

[14] Wiliam, D. (2013). Assessment: The Bridge between Teaching and Learning. Voices from the Middle, 21(2), 15-20.

[15] Aziz, S., Mahmood, M., \& Rehman, Z. (2018). Implementation of CIPP model for quality evaluation at school level: A case study. Journal of Education and Educational Development, 5(1), 189-206. https://doi.org/10.22555/joeed.v5i1.1553

[16] Marlina, E., Putri, R.I.I., \& Darmawijoyo. (2019). Developing Problem High Order Thinking Type Application Volume Cube and Cuboid Based Problem Based Learning for Secondary School. International Journal of Active Learning, 4(1), 33-39. https://doi.org/10.15 294/ijal.v4i1.15119

[17] Ariawan, I.P.W., Simatupang, W., Ishak, A.M., Agung, A.A.G., Suratmin, Adiarta, A. , \& Divayana, D.G.H. (2018). Development of ANEKA Evaluation Model Based on Topsis in Searching the Dominant Aspects of Computer Learning Quality Determinants. Journal of Theoretical and Applied Information Technology, 96(19), 6580- 6596.

\section{Author}

Dewa Gede Hendra Divayana is with Universitas Pendidikan Ganesha in Indonesia.

Article submitted 2018-01-26. Resubmitted 2019-07-03. Final acceptance 2019-07-03. Final version published as submitted by the authors. 